\title{
Letter \\ Prognostic utility of RIFLE for acute renal failure in patients with sepsis
}

\author{
José António Lopes ${ }^{1}$, Sofia Jorge ${ }^{1}$, Cristina Resina ${ }^{1}$, Carla Santos², Álvaro Pereira² ${ }^{2}$ José Neves$^{2}$, \\ Francisco Antunes ${ }^{2}$ and Mateus Martins Prata ${ }^{1}$
}

\begin{abstract}
${ }^{1}$ Department of Nephrology and Renal Transplantation, Hospital de Santa Maria, Av. Prof. Egas Moniz, 1649-035, Lisboa, Portugal
${ }^{2}$ Department of Infectious Diseases, Hospital de Santa Maria, Av. Prof. Egas Moniz, 1649-035, Lisboa, Portugal
\end{abstract}

Corresponding author: José António Lopes, jalopes93@hotmail.com

Published: 5 April 2007

This article is online at http://ccforum.com/content/11/2/408

(c) 2007 BioMed Central Ltd

Acute renal failure (ARF) is common among patients with sepsis and increases mortality [1]. However, the prognostic utility of the newly released classification for ARF, entitled RIFLE (Risk, Injury, Failure, Loss, and End-stage kidney disease) [2], in predicting mortality in such patients has not yet been assessed. We sought to evaluate retrospectively the usefulness of RIFLE in predicting mortality in patients with sepsis admitted to the infectious disease intensive care unit (ICU) of our hospital between January 2005 and December 2006. Data were collected from the unit database. Sepsis was classified in accordance with American College of Chest Physicians and the Society of Critical Care Medicine consensus [3]. Patients with chronic kidney disease on dialysis were excluded from the analysis. The Simplified Acute Physiology Score (SAPS) version II was calculated based on the worst variables recorded during the first 24 hours of ICU admission. Mortality was assessed at day 60 [2]. Forward stepwise multivariate regression analysis was employed to evaluate independent predictors of mortality. The goodness-of-fit was tested by means of the HosmerLemeshaw statistic. Area under the receiver operating characteristic curve (AUROC) was employed to evaluate the prognostic accuracy of RIFLE and SAPS II. A two-tailed $P<0.05$ was considered statistically significant.

One-hundred and eighty-two patients (mean age $56.2 \pm 18.56$ years; 120 male; 162 white) were analyzed. Fourteen patients had sepsis, 108 patients had severe sepsis and 60 patients had septic shock. Sixty-eight patients (37.4\%) had ARF: 11 patients were in class 'risk' (in RIFLE), 21 patients were in class 'injury', and 36 patients were in class 'failure'. The mortality rate was $37.4 \%$, and increased from classes 'normal' to 'failure' (normal, 9.6\%; risk, 27.3\%; injury, 28.6\%; failure, 55\%; $P<0.0001$ ). Multivariate analysis including age above 60 years, sex, SAPS II above 50,
Critical Care 2007, 11:408 (doi:10.1186/cc5722)

comorbidity (namely cardiovascular disease), and RIFLE class revealed that SAPS II score above 50 (odds ratio 0.12, 95\% confidence interval $[\mathrm{Cl}] 0.04-0.29 ; P<0.0001)$ and class 'failure' (odds ratio $3.59,95 \% \mathrm{Cl} 1.44-8.94 ; P=0.006$ ) were independent predictors of mortality. Similarly, SAPS II score above 50 (AUROC 0.778, 95\% Cl 0.694-0.863; $P<0.0001$ ) and ARF according to RIFLE (AUROC $0.725,95 \% \mathrm{Cl}$ $0.63-0.81 ; P<0.0001)$ had good prognostic accuracy.

In summary, ARF, based on RIFLE criteria, is common in patients with sepsis, and is associated with increased mortality. RIFLE appears to be a useful prognostic tool in such patients.

\section{Competing interests}

The authors declare that they have no competing interests.

\section{Authors' contributions}

JAL, SJ, CR and CS made substantial contributions to the study concept and design, acquisition of data, and analysis and interpretation of data. JAL, CR, AP, JN, FA and MMP were involved in drafting the manuscript and revising it critically for important intellectual content. All authors gave final approval of the version to be published.

\section{References}

1. Brun-Buisson C, Meshaka P, Pinton P, Vallet B; EPISEPSIS Study Group: EPISEPSIS: a reappraisal of the epidemiology and outcome of severe sepsis in French intensive care units. Intensive Care Med 2004, 4:580-588.

2. Bellomo R, Ronco C, Kellum JA, Mehta, RL, Palevsky P and the ADQI workgroup: Acute renal failure - definition, outcome measures, animal models, fluid therapy and information technology needs: the Second International Consensus Conference of the Acute Dialysis Quality Initiative (ADQI) Group. Crit Care 2004, 8:R204-R212.

3. Levy MM, Fink MP, Marshall JC, Abraham E, Angus D, Cook D, Cohen J, Opal SM, Vincent JL, Ramsay G: 2001 SCCM/ESICM/ ACCP/ATS/SIS International Sepsis Definitions Conference. Crit Care Med 2003, 4:1250-1256.

$\mathrm{ARF}=$ acute renal failure; $\mathrm{AUROC}=$ area under the receiver operating characteristic curve; $\mathrm{Cl}=$ confidence interval; RIFLE $=$ Risk, Injury, Failure, Loss, and End-stage kidney disease; SAPS = Simplified Acute Physiology Score. 